\title{
CRESCIMENTO ECONÔMICO, EXPORTAÇÕES E TECNOLOGIA: O CASO PARANAENSE
}

\section{ECONOMIC GROWTH, EXPORTS AND TECHNOLOGY: THE PARANAENSE CASE}

\author{
Eduarda Machoski \\ Universidade Federal da Paraíba - João Pessoa - PB - Brasil \\ Augusta Pelinski Raiher \\ Universidade Estadual de Ponta Grossa - Ponta Grossa - PR - Brasil
}

\begin{abstract}
Resumo: O presente trabalho investigou a relação existente entre a estrutura da pauta exportadora paranaense e o seu crescimento econômico. Para isso, coletaram-se dados acerca de suas exportações no decorrer dos anos de 1989 a 2010 (siteAliceweb), classificando-as em níveis tecnológicos conforme a metodologia utilizada por Furtado e Carvalho (2005). Na sequência, foram calculados os índices de Diversificação, de Vantagem Comparativa Revelada - VCR e de Lawrence - $L$, visando analisar o comportamento das exportações do Estado ao longo do tempo. $\mathrm{Na}$ última parte deste trabalho, fez-se uma estimativa econométrica do Vetor Autor Regressivo VAR a fim de verificar a relação entre a composição das exportações e o crescimento econômico do Paraná.
\end{abstract}

Palavras-chave: Exportação. Intensidade tecnológica. Crescimento econômico. Paraná.

Abstract: This study aimed to investigate the relationship between the structure of Paraná's export basket and the economic growth of the State. To do that, we collected data concerning of Paraná exports for the period of 1989-2010 (Aliceweb website), classifying them into technological levels according to the methodology used by Furtado and Carvalho (2005). Furthermore, rates of diversification, Revealed Comparative Advantage and Lawrence were calculated, in order to analyze the behavior of the State's exports over time. In the last part of this work, was estimated an econometric model (VAR) to analyze the relationship between the composition of exports and the economic growth of Paraná.

Keywords: Export; Technological intensity; Economic growth; Paraná

\section{INTRODUÇÃO}

Até o final dos anos de 1980, o Brasil apresentou uma postura protecionista para com o seu mercado, atrelado à política de substituição das importações. Principalmente a partir da década de 1990, a política de comércio exterior se alterou significativamente, com um processo de abertura comercial abrangente - a qual teve início no governo Collor e se estendeu até o de Fernando Henrique Cardoso, juntamente com o processo de integração comercial brasileira. (AVEBURG, 2011).

Foi exatamente nesse período em que o Brasil intensificou o processo de abertura comercial que se acentuou o debate acerca de como o comércio internacional afeta o crescimento econômico. De um lado, um grupo de autores defende a abertura comercial como dinamizadora do crescimento econômico 
(como Feder, 1983; North, 1955) ao passo que, o outro grupo ${ }^{1}$ afirma que o comércio internacional prejudica o crescimento, seja pelas distorções nos termos de troca ou pela incapacidade dessas economias em incorporar novas tecnologias.

Para os primeiros, a abertura comercial facilita a inovação por meio da importação de bens com alto teor tecnológico, além de aumentar o tamanho dos mercados, permitindo que as economias se beneficiem dos retornos crescentes de escala e dos ganhos de especialização (BARRO e SALA-IMARTIN, 1997). Ao mesmo tempo, a argumentação principal do segundo grupo é a de que, se a promoção do comércio internacional de um país conduzir a sua especialização em setores de baixa tecnologia, pode-se ter uma deterioração dos seus termos de troca, podendo a abertura afetar até mesmo negativamente o seu crescimento econômico (GROSSMAN E HELPMAN, 1990).

No entanto, por mais que existam prejuízos para algumas nações/regiões ao intensificarem o comércio internacional, a base da teoria econômica, por alegações diversas, chega ao mesmo ponto quanto à necessidade de ampliar o mercado (indo além do interno) para manter o dinamismo econômico (NORTH, 1955; FELDER, 1983, CRESPO-CUARESMA e WÖRZ, 2003).

Nesse sentido que se justifica este trabalho, questionando se a composição das exportações do Paraná se modificou em paralelo às transformações da política de comércio exterior do Brasil, com alteração para produtos de maior valor agregado (mais intenso em tecnologia) e se essas exportações influenciaram o crescimento econômico, tendo em vista que autores, como North (1955) colocam a demanda internacional como a grande fomentadora do crescimento de uma região.

Com efeito, o objetivo é o de verificar a existência de uma relação entre a composição das exportações e o crescimento da economia paranaense, no período de 1989 a 2010, especificadamente, busca identificar os produtos exportados pelo Paraná ao longo de tempo; classificar esses produtos em níveis tecnológicos, analisando a participação de cada nível tecnológico na exportação total e; analisar se existe relação entre a composição das exportações paranaenses e o crescimento da economia do Estado no período estudado.

\section{EXPORTAÇÕES E CRESCIMENTO ECONÔMICO: O MODELO DE FEDER}

O modelo de Feder (1983)afirma que as exportações tendem a influenciar o crescimento econômico de forma positiva. Nesse modelo, a economia é dividida em dois setores: não exportador (ou doméstico) e exportador. Assim, existe uma tendência de as produtividades marginais dos fatores de produção do setor exportador serem maiores que no setor não exportador. Além disso, Feder (1983) afirma que o setor exportador gera externalidades positivas intersetoriais sobre toda a economia. Essas externalidades estariam ligadas aos ganhos dinâmicos do setor exportador, tais como a produtividade marginal com valores mais elevados.

A formalização racional do modelo de Feder (1983) parte do princípio que a função de produção do setor doméstico $(N)$ e do setor exportador $(X)$ é resultante de dois fatores: capital $(K)$ e trabalho $(L)$. Além desses dois fatores, na função de

\footnotetext{
${ }^{1}$ Argumentações apresentadas em Grossman e Helpman (1990), Araújo e Lima (2007), dentre outros.
} 
produção do setor doméstico, é considerado também o total de todas as exportações. Dessa forma, "o autor abarca em sua formulação tanto a possibilidade de uma alocação não ótima dos recursos, quanto a possibilidade de geração de externalidades do setor exportador para o resto da economia" (GALIMBERTI, 2007, p.28). Partindo dessas considerações, tem-se a função de produção do setor doméstico (2.1) e a do exportador (2.2):

$$
\begin{array}{r}
\mathrm{N}=\mathrm{F}\left(\mathrm{K}_{\mathrm{n},}, \mathrm{L}_{\mathrm{n}}, \mathrm{X}\right) \\
\mathrm{X}=\mathrm{G}\left(\mathrm{K}_{\mathrm{X}}, \mathrm{L}_{\mathrm{x}}\right)
\end{array}
$$

Para a solução do modelo, Feder (1983) pressupõe que a razão entre as produtividades marginais dos fatores, em cada setor, desvia da unidade em consequência de um fator $(\delta)$.

$\mathrm{Na}$ equação (2.3),GK, GL, FK e FL representam as produtividades marginais de cada fator de produção nos dois setores:

$$
\frac{\mathrm{G}_{\mathrm{k}}}{\mathrm{F}_{\mathrm{k}}}=\frac{\mathrm{G}_{\mathrm{l}}}{\mathrm{F}_{\mathrm{l}}}=1+\delta
$$

Dados os preços, uma situação de ausência de externalidades, onde $\delta=0$, refletiria uma alocação de recursos que maximiza a produção total. Porém, o modelo de Feder (1983) supõe que a produtividade marginal do setor doméstico tende a ser menor que a do setor exportador, ou seja, $\delta>0$.

Dessa forma, conforme feito por Galimberti e Caldart (2010, p. 87), "procedendo-se à diferenciação das funções de produção de cada setor em relação ao tempo, considerando-se que o produto de uma economia é igual a soma dos dois setores e dividindo a equação diferencial por $Y^{\prime \prime}$, chega-se à equação 2.4.

$$
\frac{\dot{Y}}{Y}=F_{K} \cdot\left(\frac{I}{Y}\right)+F_{L} \cdot\left(\frac{\dot{L}}{Y}\right)+\left(\frac{\delta}{(1+\delta)}\right) \cdot\left(\frac{\dot{X}}{Y}\right)+F_{X} \cdot\left(\frac{\dot{X}}{Y}\right)
$$

Faz-se importante destacar que essa formulação não possibilita distinguir o efeito das externalidades do efeito alocativo das exportações (GALIMBERTI e CALDART, 2010). É nesse ponto que Feder (1983) conjectura que a intensidade desse efeito externalidade é uma função da relação existente entre a produção do setor doméstico (não exportador) e a produção do setor exportador, conforme a equação a seguir:

$$
F_{X}=\phi \cdot\left(\frac{Y-X}{X}\right)
$$

Isso posto, pode-se constatar que quanto menor for a participação do setor exportador no total da economia, maior será o efeito das externalidades sobre esta. Nesse pressuposto, fica subentendida a ideia de que esse efeito possui um limite, o qual é determinado de acordo com o atual nível de extroversão da economia (GALIMBERTI E CALDART, 2010. p.97).

Ademais, Feder (1983) pressupõe também que existe uma relação linear entre a produção media por trabalhador na economia e a produtividade marginal do trabalho em um dado setor, sendo este pressuposto estendido também ao fator capital, conforme as equações 2.6 e 2.7 .

$$
\begin{aligned}
& F_{L}=\beta \cdot \frac{Y}{L} \\
& F_{K}=\alpha \cdot \frac{Y}{K}
\end{aligned}
$$

Substituindo-se $\left(\frac{\delta}{1+\delta}\right)$ por $(\lambda)$, chega-se à formulação base (equação 2.8 ) para o estudo empírico de Feder (1983). Pode-se notar que se as produtividades 
marginais forem iguais entre os dois setores $(\delta=0)$ e se não existirem externalidades entre estes $\left(F_{X}=0^{2}\right.$, ) então a equação (3.4) reduz-se à formulação neoclássica do crescimento econômico (GALIMBERTI, 2010). Destacando que a variável I refere-se ao investimento, tem-se:

$$
\frac{\dot{\mathrm{Y}}}{\mathrm{Y}}=\alpha \cdot\left(\frac{\mathrm{I}}{\mathrm{Y}}\right)+\beta \cdot\left(\frac{\dot{\mathrm{L}}}{\mathrm{L}}\right)+\lambda \cdot\left(\frac{\dot{X}}{X}\right) \cdot\left(\frac{X}{\mathrm{Y}}\right)+\phi \cdot\left(\frac{\dot{\mathrm{X}}}{\mathrm{X}}\right) \cdot\left(\frac{\mathrm{Y}-\mathrm{X}}{\mathrm{Y}}\right)
$$

A partir da formalização desse modelo, durante os anos de 1964 a 1973, Feder (1983) utilizou dados de algumas economias semi-industrializadas, que adotaram políticas de promoção das exportações para testar a relação entre o setor exportador e o crescimento econômico.

Os estudos de Feder (1983) concluíram que o crescimento econômico pode ser gerado não só pelo aumento dos níveis agregados de capital ( $K$ ) e trabalho $(L)$, mas que políticas que fomentam as exportações também promovem o crescimento econômico, pois acabam por induzir a economia a operar em um nível de alocação dos recursos mais próximo do ideal (PINHEIRO, 1992).

Portanto, conforme esse modelo, o crescimento de uma economia pode ser obtido por meio da alocação dos recursos existentes do setor menos eficiente (não exportador) para o setor mais eficiente (exportador) dessa economia.

\title{
2.1 Composição das Exportações e Crescimento Econômico
}

Crespo-CuaresmaeWörz (2003), assim como Feder (1983), ressaltam o papel das exportações direta e indiretamente para o crescimento do produto e, consequentemente, para o crescimento da renda de uma economia:

\begin{abstract}
No entanto, há uma série de razões pelas quais o impacto das exportações deve ser maior que o valor puro de variação. O crescimento indireto promove efeitos que podem ocorrer devido às economias de escala, ao aumento da utilização de capacidade, aos ganhos de produtividade, à maior variedade de produtos, etc. (CRESPOCUARESMA e WÖRZ, 2003, p.2, tradução nossa).
\end{abstract}

Um fator importante a ser ressaltado a respeito do efeito das exportações sobre o crescimento econômico deriva do fato de que uma maior exposição comercial resulta em uma pressão sobre a economia, no que se refere à modernização tecnológica de sua produção.

Em seu trabalho, Crespo-Cuaresma e Wörz (2003) refinam a teoria ricardiana e apresentam o postulado de que não apenas o crescimento das exportações importa no crescimento econômico, mas também a composição das mesmas. Os autores atribuem um papel crucial à composição da pauta exportadora e deslocam sua ênfase de um menor nível de agregação para a mesoestrutura da economia.

Crespo-Cuaresma e Wörz (2003) defendem a hipótese de que os setores mais intensos em tecnologia implicam em um maior ganho de produtividade e em mais externalidades positivas que os setores menos sofisticados. Assim sendo, a

\footnotetext{
${ }^{2} F x$ : externalidades positivas que as exportações causam sobre a economia.
} 
composição das exportações acaba por possuir uma influência decisiva sobre o crescimento de uma economia (GALIMBERTI, 2007).

Desse modo, a partir do modelo de Feder (1983), Crespo-Cuaresma e Wörz (2003) formulam um modelo que objetiva testar explicitamente sua hipótese. A generalização do modelo de Feder (1983) acontece a partir da consideração de que o setor exportador é constituído de diversos subsetores. A equação (2.9) mostra o resultado:

$$
\frac{\dot{Y}}{\mathrm{Y}}=\alpha \cdot\left(\frac{\mathrm{I}}{\mathrm{Y}}\right)+\beta \cdot\left(\frac{\dot{\mathrm{L}}}{\mathrm{L}}\right)+\sum_{\mathrm{i}=1}^{\mathrm{s}}\left[\Psi_{\mathrm{i}}\left(\frac{\dot{\mathrm{X}}_{1}}{\mathrm{X}_{\mathrm{i}}}\right) \cdot\left(1-\frac{\sum_{\mathrm{i}=1}^{\mathrm{S}} \mathrm{X}_{\mathrm{i}}}{\mathrm{Y}}\right)+\left(\frac{\mathrm{d}_{\mathrm{i}}}{\left(1+\mathrm{d}_{\mathrm{i}}\right)}\right) \cdot\left(\frac{\dot{X}_{1}}{\mathrm{X}_{\mathrm{i}}}\right) \cdot\left(\frac{\mathrm{X}_{\mathrm{i}}}{\mathrm{Y}}\right)\right]
$$

A equação (2.9) é elaborada para $S$ setores e tem por finalidade verificar a existência de diferenças entre três setores exportadores: de não-manufaturados, de manufaturados de baixa tecnologia e de manufaturados de alta tecnologia.

No período de 1981 a 1997, Crespo-Cuaresma e Wörz (2003) realizaram um estudo abrangendo as exportações de 33 indústrias em 45 países industrializados e em fase de desenvolvimento. A conclusão obtida através do estudo é de que países em desenvolvimento obtêm proveitos, principalmente, a partir da alocação eficiente de recursos advinda, por sua vez, da abertura comercial focada nas exportações. Ao contrário do que se acreditava na época, a competição internacional decorrente da abertura comercial foi notada como determinante do crescimento econômico e não o efeito de aprendizagem e tantas outras externalidades positivas.

Além disso, observaram que a produtividade diferenciada do setor exportador não se concretizou, de fato, em todas as indústrias. Notou-se uma produtividade elevada apenas nos setores exportadores de produtos nãomanufaturados e de manufaturados de alta intensidade tecnológica. O setor de exportação de produtos manufaturados de baixa tecnologia apresentou produtividade relativamente baixa em comparação aos outros dois setores.

O impacto das exportações ou da composição destas sobre o crescimento econômico tem sido objeto de estudo de muitos outros autores. Amable (2000), Laursen (2000) e Peneder (2002), por exemplo, analisaram o efeito da especialização industrial em indústrias específicas. Os estudos dos três autores concluíram que existe um impacto positivo da especialização industrial sobre o crescimento econômico. Amable (2000) identificou a especialização principalmente em indústrias de bens eletrônicos - como propulsora de crescimento. Do mesmo modo, Laursen (2000) obteve resultados semelhantes, defendendo que a especialização em setores de rápido crescimento (que correspondem, em geral, a setores de alta intensidade tecnológica) está altamente relacionada ao crescimento da renda de uma economia. Por fim, Peneder (2002) concluiu em seus estudos que, enquanto a especialização no setor de serviços representa um empecilho para o crescimento futuro, a especialização em indústrias de alta intensidade tecnológica tem efeitos positivos e propulsores do crescimento.

Dessa forma, a hipótese de Crespo-Cuaresma e Wörz (2003) de que o crescimento econômico de uma economia depende da intensidade tecnológica de suas exportações encontra suporte na literatura econômica. 


\section{METODOLOGIA}

Foram coletados do site AliceWeb os dados acerca das exportações paranaenses para o período de 1989 a 2010, todos deflacionados pelo Índice de Preços ao Consumidor - IPC americano - $2005=100$ (IPEADATA). Tais dados constituíam 97 itens, que foram classificados por nível tecnológico baseando-se na metodologia usada por Furtado e Carvalho (2005): Alta intensidade tecnológica (setores aeroespacial; farmacêutico; de informática; eletrônica e telecomunicações $\mathrm{e}$; instrumentos médicos); Média-alta intensidade tecnologia (setores de material elétrico; veículos automotores; química, excluído o setor farmacêutico; ferroviário e de equipamento de transporte; máquinas e equipamentos); Média-baixa intensidade tecnológica (setores de construção naval; borracha e produtos plásticos; coque, produtos refinados do petróleo e de combustíveis nucleares; outros produtos não metálicos; metalurgia básica e produtos metálicos); Baixa intensidade tecnológica (outros setores e de reciclagem, papel e celulose; editorial e gráfica; alimentos, bebidas e fumo; têxtil e de confecção, couro e calçados); Produtos não industriais.

Com o objetivo de analisar a estrutura exportadora da economia paranaense, calculou-se os Índices de Vantagem Comparativa Revelada - VCR e de Lawrence - L. O VCR é um indicador que permite mensurar a importância de determinado produto ou setor na pauta exportadora de uma economia (RIBEIRO, 2010). Para isso, o índice divide a porcentagem de exportações de determinado setor numa economia pela porcentagem das exportações desse mesmo setor em uma economia a ser comparada.

Quando o VCR apresenta valores mais próximos de uma unidade, maior é a especialização da economia neste setor ou nível. Por outro lado, para valores inferiores a uma unidade, a economia possui desvantagem em produzir bens desse setor, pois menor é a sua especialização neste nível.

Por seguinte, por meio do $L$ mensurou-se o grau de transformação da estrutura exportadora paranaense (3.1). Tal índice varia entre 0 e 1, apresentando valores mais elevados conforme maior for a mudança ocorrida na estrutura da economia durante o período analisado (RIBEIRO, 2010).

$$
L=\frac{1}{2} \sum_{i=1}^{5}\left|S_{i, t}-S_{i, t-1}\right|
$$

em que: $\boldsymbol{S}_{\boldsymbol{i}, \boldsymbol{t}}=\frac{\boldsymbol{x}_{\boldsymbol{i}, \boldsymbol{t}}}{\sum \boldsymbol{x}_{\boldsymbol{i}, \boldsymbol{t}}}$ é o peso das exportações de cada setor no total das exportações de uma economia em um determinado período (t).

\subsection{Crescimento Econômico e seus Determinantes}

Feder (1983) argumenta em seu modelo que para se alcançar o crescimento econômico, deve-se realocar os fatores de produção do setor menos eficiente (não exportador) para o mais eficiente (exportador). Segundo o autor, o setor exportador apresenta produtividades marginais dos fatores de produção significativamente maiores que as observadas no setor não exportador. Além disso, defende a existência de externalidades positivas advindas do setor exportador para a economia como um todo.

Nessa linha de argumentação, Crespo-Cuaresma e Wörz (2003) ampliam o modelo de Feder, segmentando essa inserção internacional, com o argumento de 
que os ganhos oriundos das exportações dependem da intensidade tecnológica da pauta exportadora.

Assim, dividiu-se a exportaçãodo Paraná em duas categorias ${ }^{3}$ : bens intensivos em tecnologia (média alta e alta tecnologia $\left.=X_{H T}\right)^{4}$ e outros bens (abrangendo os níveis tecnológicos de média-baixa e baixa intensidade tecnológica e outros produtos não industriais $=X_{W T}$ ).

Ressalta-se que não se utilizou os valores diretos das exportações, mas sim, os seus resultados indiretos (via a produtividade e externalidade), conforme equação (2.9). Ou seja, estimou a resposta da taxa de crescimento do PIB per capita $\left(\mathrm{PIB}_{\mathrm{per}}\right)$ paranaense dado uma alteração nas seguintes variáveis: externalidade das exportações dos bens mais intensivos em tecnologia [EXT. $X_{H T}$ obtido por $\left(\frac{\Delta X_{, i t}}{X_{, i t}}\left(1-\frac{\sum X_{, i t}}{Y_{i t}}\right)\right)$, destacando que $X$ são as exportações, $Y$ é o PIB, $i$ é segmento, té o tempo]; externalidade dos outros bens $\left(E X T X_{w t}\right)$; produtividade da exportações dos bens mais intensivos em tecnologia [PROD $X_{H \pi}$ auferida por meiode $\left(\frac{\Delta X_{i t}}{X_{, i t}} \frac{X_{i t}}{Y_{i t}}\right)$ ]; produtividade da exportação de outros bens (PROD $\left.X_{W T}\right)$, e; alterações no capital físico (KF), obtida pela taxa de crescimento do capital físico como proporção do PIB ${ }^{5}$.

A despeito da metodologia utilizada na estimação, aplicou-se o modelo de $V A R$, o qual defende a premissa que todas as variáveis no modelo devem ser tratadas de forma simultânea e simétrica. O VAR consiste de um conjunto de $k$ variáveis endógenas $y t=\left(y_{1 t}, . ., y_{k t}, \ldots, y_{k t}\right)$ para $k=1, \ldots, k$, sendo definido por Gomes e Fantinel (2014):

$$
y_{t}=A_{1} y_{t-1}+\ldots+A_{p} y_{t-p}+B X_{t}+\varepsilon_{t}
$$

Em que: $\boldsymbol{A}_{i} \boldsymbol{i}=1,2, \ldots, p$ se refere às matrizes $(K x K)$ com os parâmetros das equações; $\boldsymbol{\varepsilon}_{\mathrm{t}}$ são os erros não correlacionados, com média zero e variância constante e; $p$ é número de defasagens a serem incluídas no modelo. Ao utilizar três critérios [Akaike (AIC), Bayesiano de Schwarg (BIC) e de Hannan-Quinn (HQC)], optou-se por duas defasagens (Apêndice A). ${ }^{6}$

A série utilizada na pesquisa refere-se ao período de 1989 a 2010, sendo: EXT $X_{H T} ;$ EXT $X_{W T} ;$ PROD $X_{H T} ;$ PROD $X_{W T} ; K F e, P I B_{P E R}$. A ideia é testar se esta última responde aos choques das externalidades das exportações mais intensivas e menos intensivas em tecnologia, à produtividade das exportações mais intensivas e menos intensivas em tecnologia e ao capital físico. Vale ressaltar que a aplicação de tal metodologia requer uma ordenação das variáveis, efetivada da variável teoricamente mais exógena para a mais endógena, a saber: EXT $X_{H T ;}$ EXT $X_{W T}$; $P R O D X_{H T} ;$ PROD $X_{W T} ; K F$ e, PIB $B_{P E R}$. Ressalta-se que foram utilizados dummies com

\footnotetext{
${ }^{3}$ Metodologia semelhante à de Galimberti (2007).

${ }^{4}$ Justifica-se que agregou-se a alta tecnologia com a média alta tendo em vista que autores, como Lamonica e Feijó (2011), defendem que tanto a alta como a média alta tecnologia são intensivas em capital e tecnologia, diferenciando-se dos demais grupos.

${ }^{5} \mathrm{~A}$ fonte dos dados originais foi o site AliceWeb (para as exportações), Ipeadata (para o PIB, a preços constantes de 2000, e para o câmbio real) e Ipardes (para a população, energia elétrica do setor secundário, a qual é a proxy para o capital físico, e tarifa da energia do setor industrial).

${ }^{6}$ Problema de autocorrelação não foi identificada (Ljung-Box:1,4), e os resíduos apresentaram uma distribuição normal (teste Doornik-Hansen: 9,3).
} 
o intuito de controlar quebras nas séries (introdução do Plano Real), conforme detectado pelo teste Chow ${ }^{7}$.

\section{CRESCIMENTO ECONÔMICO E AS EXPORTAÇÕESPARANAENSES}

Autores como Feder (1983) e North (1955) demonstram a relação positiva existente entre as exportações e o crescimento econômico de uma região. Dentre as mais recentes, cita-se a de Feder (1983), segundo a qual, a inserção no mercado externo se torna indispensável para o crescimento econômico de uma região. Neste sentido, esta seção apresenta inicialmente a evolução das exportações do Estado do Paraná, sua composição em termos tecnológicos, finalizando com a análise empírica acerca da relação existente entre o crescimento econômico e a inserção no mercado internacional.

\subsection{Evolução e Composição das Exportações Paranaenses}

O Estado do Paraná, no decorrer de sua história, passou por diferentes ciclos. Em síntese, pode-se dizer que até os anos de 1960 a agricultura era a base de sua economia. Nos anos de 1970, acompanhando o movimento nacional, a agricultura entra num processo de modernização e a indústria se torna relevante para a economia paranaense, destacando, contudo, que essa indústria estava atrelada significativamente ao setor primário. Somente no decorrer da década de 1990, com diferentes ações executadas pelo governo (incentivos fiscais, financiamentos, entre outros), é que o Paraná se torna um estado industrializado de fato, tendendo a mudar a sua especialização produtiva. E a sua inserção internacional potencialmente percorreu o mesmo caminho.

Com efeito, em termos de evolução, as exportações brasileiras tiveram um crescimento modesto entre 1989 e 2010, passando de US\$ 54 bilhões para US\$ 149 bilhões em 2010, crescimento de cerca de 175\%. Já o Paraná passou de aproximadamente US\$ 1 bilhão em 1989 para mais de US\$ 12 bilhões em 2010, acrescendo em 12 vezes suas exportações. Ou seja, a inserção internacional do Paraná foi bem superior à brasileira (IPEADATA, 2013).

De forma específica, entre 1989 e 1994 o estado exportou aproximadamente os mesmos montantes. Segundo Lourenço (2005), o aprofundamento da abertura econômica, a desregulamentação dos mercados e o início do processo de privatização ocorrido na economia brasileira no começo dos anos 1990 levaram a economia brasileira como um todo a um clima de recessão, refletindo também na dinâmica paranaense.

A partir de 1994, a inserção internacional do Paraná ganhou ênfase. Mesmo no período inicial do Plano Real, em que se teve uma apreciação cambial, o crescimento de suas exportações continuou intenso. Como as empresas nacionais não se encontravam providas de condições técnicas, financeiras e de tempo para se prepararem, a abertura econômica iniciada no Brasil e o clima de recessão do período provocaram um movimento defensivo no setor privado, conhecido como reestruturação industrial, que, em alguma medida, contribuiu para o aumento da competitividade interna.

\footnotetext{
${ }^{7}$ Valor igual a $41,8$.
} 
Nesse contexto, aliado a esse cenário, utilizou-se de um conjunto de fatores visando a sua inserção internacional, tais como a sua localização geográfica privilegiada (proximidade com os países do Mercado Comum do Sul - MERCOSUL e com os maiores centros do país, especialmente São Paulo), e a infraestrutura propícia juntamente com os mecanismos institucionais adequados para a expansão e implantação de novas indústrias. Iniciou-se, assim, um ciclo de investimentos estruturantes, com destaque para a modernização agrícola, ampliação qualitativa e quantitativa do setor madeireiro e papeleiro e, principalmente, o desenvolvimento do polo automobilístico no estado (MIGLIORINI, 2006). Com efeito, essas mudanças que ocorreram certamente melhoraram a competitividade dos produtos paranaenses, justificando, em parte, a crescente inserção do estado no mercado internacional.

Outro fator importante na fomentação das exportações refere-se à diversificação da pauta exportadora paranaense. A Tabela 1 mostra os resultados obtidos para o Índice de Diversificação calculado para as exportações do estado ${ }^{8}$, no período de 1989 a 2010, na qual se percebe uma alta diversificação; ressalta-se que o valor do índice praticamente não se alterou, contudo, como manteve-se próximo a 1, isso demonstra o elevado grau de diversificação da pauta de exportação paranaense. Ora, a diversificação em termos da participação dos produtos no total exportado é vista por muitos autores como benéfica, uma vez que reduz os riscos associados a possíveis oscilações de preços e de demanda externa, proporcionando estabilidade às exportações e, por consequência, à economia.

Dessa forma, ao mesmo tempo em que se tem um aumento do volume (em termos monetários) exportado pelo Paraná, ele não se restringe apenas a alguns produtos, diminuindo a vulnerabilidade do estado frente às oscilações da demanda internacional.

Outra informação que vem a contribuir com os dados apresentados na Tabela 1 refere-se ao número de produtos exportados pelo estado. A classificação do site AliceWeb usada nesta pesquisa é a CAPÍTULO - SH 2 DÍGITOS, que abrange 97 produtos, e o Paraná, entre 1989 e 2010, exportou entre 36 e 55 bens desta classificação. Ou seja, é elevado o número de produtos exportados pelo Paraná e a participação destes produtos no total exportado é bastante equitativa.

Tabela 1. Índice de Diversificação das Exportações Paranaenses

\begin{tabular}{|c|c|c|c|c|c|c|c|c|c|c|c|c|c|c|c|c|c|c|c|c|}
\hline $\begin{array}{l}\stackrel{\leftrightarrow}{\infty} \\
\stackrel{2}{\sigma}\end{array}$ & ஓ & হ̄ & ๙ু & §ু & Љু & 命 & ু̆ & $\begin{array}{l}\infty \\
\stackrel{్}{\sigma}\end{array}$ & ু & $\underset{\sim}{\stackrel{D}{ }}$ & $\bar{\delta}$ & రి & ஜి & ষ্ণ & ஜి & రి & ঠి & $\stackrel{\infty}{\stackrel{\infty}{~}}$ & ஜे & $\stackrel{\circ}{\frac{0}{2}}$ \\
\hline $\begin{array}{l}0 \\
\infty \\
0^{\circ}\end{array}$ & $\begin{array}{l}\text { గิ } \\
\text { O }\end{array}$ & $\bar{\sigma}$ & б. & $\begin{array}{l}\alpha \\
\sigma \\
0\end{array}$ & $\begin{array}{l}\text { గิ } \\
\text { - }\end{array}$ & مू & $0^{\circ}$ & $\begin{array}{l}8 \\
0 \\
0\end{array}$ & 8. & $\begin{array}{l}\text { 8) } \\
0\end{array}$ & $\begin{array}{l}8 \\
0 \\
0\end{array}$ & 8. & б్ & б. & $0^{\circ}$ & $\begin{array}{l}\alpha \\
\text { Oू } \\
\end{array}$ & $\begin{array}{l}\text { గ్ } \\
\text { - }\end{array}$ & $\begin{array}{l}\text { Nิ } \\
\text { o }\end{array}$ & 0 & 0 \\
\hline
\end{tabular}

Fonte: Dados trabalhados pela pesquisa.

\footnotetext{
${ }^{8} \mathrm{O}$ Índice de diversificação utilizado foi o Índice de Hirschman-Herdfindhal $(\mathrm{H}-\mathrm{H})$, definido por: $H=\sum_{i=1}^{n}\left(\frac{X_{i}}{\sum_{j=1}^{n} X_{j}}\right)^{2}=\sum_{i=1}^{n} S_{i}^{2}$
}

Em que: $S_{i}$ representa a participação do i-ésimoitem de exportação $\left(X_{i}\right)$ sobre o total das exportações.O resultado de $\mathrm{H}-\mathrm{H}$ é subtraído da unidade, em que, quanto mais próximo de "1" mais diversificado é a pauta exportadora. 
Ao mesmo tempo em que muitos autores defendem o incremento das exportações como fator dinamizador da economia, outros vão além, classificando os produtos em níveis tecnológicos, demonstrando a importância da exportação de produtos mais intensos em tecnologia (ARAÚJO E LIMA, 2007).

Nesse sentido, classificando as exportações do Paraná em níveis tecnológicos (Figura 1), constata-se uma significativa evolução do nível de médiaalta intensidade tecnológica. De fato, as exportações desse nível tecnológico passaram de US\$ 154 milhões em 1989 para mais de US\$ 3 bilhões na média anual do período 2005-2010, um crescimento de 1834\%. Em segundo lugar, o setor de produtos não industriais apresentou um crescimento de $954 \%$ no período analisado, seguido dos setores de baixa $(819 \%)$, alta $(634 \%)$ e de média-baixa intensidade tecnológica (481\%).

Figura 1. Exportações paranaenses por intensidade tecnológica no período de 1989 a 2010 - Média anual de cada período - Milhões de dólares (deflacionados pelo IPC - EUA - $2005=100$ )

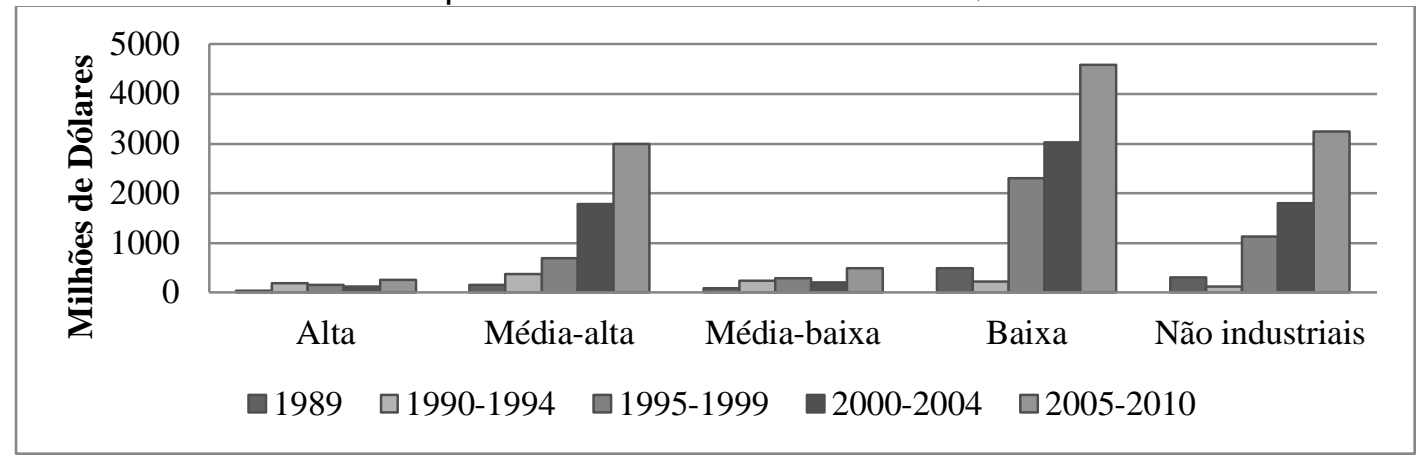

Fonte: dados coletados do siteAliceWeb trabalhados pela pesquisa.

Em 1989, o nível que predominava nos produtos exportados pelo Paraná era o de baixa intensidade tecnológica, abrangendo $46 \%$ das exportações, seguido dos produtos não industriais (28\%), dos produtos da média alta tecnologia (14\%), da média baixa (8\%) e da alta tecnologia (3\%). Na média dos anos de 2005 a 2010, os produtos da indústria de baixa tecnologia continuaram a ser o grande responsável pela inserção internacional do Paraná (40\% das exportações), seguido dos produtos não industriais (28\%), dos produtos da média alta tecnologia (26\%), da média baixa (4\%) e da alta tecnologia (2\%).

Percebe-se então que, apesar de ter se percorrido mais de quinze anos, a estrutura das exportações do Paraná praticamente não se alterou, mudando apenas a participação relativa de cada segmento, privilegiando a exportação de bens de baixa intensidade tecnológica ( $68 \%$ das exportações correspondem a bens de baixa intensidade tecnológica e de produtos não industriais).

De fato, a economia paranaense sempre apresentou sua base produtiva fortemente atrelada à atividade agropecuária e, por conta disso, é tradicionalmente exportadora de produtos deste setor. Além de apresentar um grande potencial, a atividade agrícola desempenha um importante papel na economia paranaense. Esse fato é explicado, principalmente, pelas condições climáticas favoráveis à atividade e pelas altas produtividades observadas no estado.

Um ponto importante a se destacar é o crescimento do nível de média-alta intensidade tecnológica no período estudado (cuja participação nas exportações de 
1989 era de $14 \%$ e no período de 2005-2010 passou para $24 \%$ ). Isso se deve à nova fase de industrialização ocorrida no Paraná nos anos de 1990, com a instalação de grandes empresas internacionais montadoras de veículos e fabricantes de componentes automotivos, que consolidou a Região Metropolitana de Curitiba como polo industrial e tecnológico do estado.

Diferentes índices (como o índice de vantagem comparativa, o índice de especialização produtiva, o Índice de Herfindahl-Hirschman) são utilizados para compreender melhor a estrutura exportadora de uma economia. Utilizando, inicialmente o Índice VCR, tendo como espaço de referência o Brasil, percebe-se que, em 1989, o Paraná apresentava vantagem comparativa revelada nos setores de baixa intensidade tecnológica e de produtos não industriais. Já em 2010, além desses dois setores, apresentou vantagem na exportação de média-alta intensidade tecnológica (Tabela 2).

Tabela 2. VCR do Paraná relativamente ao Brasil - 1989 e 2010

\begin{tabular}{ccc}
\hline Índice VCR & 1989 & 2010 \\
\hline Indústria de alta tecnologia & 0,56 & 0,35 \\
Indústria de média-alta tecnologia & 0,74 & 1,36 \\
Indústria de média-baixa tecnologia & 0,24 & 0,08 \\
Indústria de baixa tecnologia & 1,47 & 1,64 \\
Produtos não industriais & $\mathbf{2 , 4 7}$ & $\mathbf{1 , 9 5}$ \\
\hline
\end{tabular}

Fonte: Dados originais do AliceWeb, trabalhados pela pesquisa.

Com efeito, a fomentação da indústria metalmecânica e a instalação de diversas indústrias do polo automobilístico na Cidade Industrial de Curitiba alavancaram a mudança na estrutura produtiva que se teve nos anos de 1990 no Paraná, contribuindo para que o estado se tornasse competitivo num setor industrial cuja intensidade tecnológica é bem maior do que os produtos que se tinha vantagem em 1989. Ou seja, o Paraná continua tendo vantagens na exportação dos bens do início do período estudado, bens esses cujo nível tecnológico é relativamente baixo, mas acrescentou um setor cuja agregação de valor é significativamente maior.

Destarte, se correlacionar esses resultados quanto à VCR com a Figura (1), pode-se perceber que esses três segmentos (média-alta, baixa intensidade tecnológica e produtos não industriais) foram os que apresentaram o maior crescimento no decorrer dos anos.

Uma vez compreendidas as vantagem comparativas reveladas do Paraná, torna-se relevante verificar se houve mudança significativa na estrutura exportadora do estado durante o período analisado. Para isso, recorre-se ao Índice de Lawrence, o qual permite medir o grau de transformação da estrutura exportador de uma economia.

Pela análise da Tabela 3 infere-se que, em quase todos os anos, os resultados obtidos apresentam valores muito pequenos, sinalizando baixa mudança na estrutura exportadora paranaense. 
Tabela 3 - Índice de Lawrence para o Estado do Paraná - média anual de cada período

\begin{tabular}{cccc}
\hline $1990-1994$ & $1995-1999$ & $2000-2004$ & $2005-2010$ \\
\hline 0,16 & 0,16 & 0,04 & 0,05 \\
\hline
\end{tabular}

Fonte: Dados originais do AliceWeb, trabalhados pela pesquisa.

Torna-se importante destacar, porém, que os valores referentes à década de 1990 foram maiores que os observados para a década de 2000, demonstrando que a pouca alteração que se deu durante o período estudado, ocorreu especialmente nos anos de 1990. E isso encontra suporte, pois a nova fase de industrialização paranaense ocorreu nessa década, com a consolidação da Região Metropolitana de Curitiba, na qual diversas indústrias automotivas (média-alta intensidade tecnológica) instalaram suas fábricas.

Diante de todos esses resultados, pôde-se verificar que, no período estudado, as exportações paranaenses cresceram de forma mais intensa que as exportações brasileiras. Além disso, apesar de sua produção ainda estar fortemente ligada ao setor de baixa intensidade tecnológica e não industriais, o Paraná apresentou uma pequena mudança na sua estrutura produtiva, fomentando a exportação de bens com agregação de valor maior (média alta tecnologia).

\subsection{CRESCIMENTO ECONÔMICO E A IMPORTÂNCIA DAS EXPORTAÇÕES}

Crespo-Cuaresma e Wörz (2003) ressaltam a importância da produção de bens mais intensivos em tecnologia para o crescimento econômico. Baseando-se no mesmo pensamento, Araújo e Lima (2007) enfatizam que a forma de se impulsionar o crescimento de uma economia é a exportação de bens de níveis tecnológicos mais altos. Portanto, essa mudança percebida na estrutura exportadora do Paraná tende a contribuir positivamente para o seu crescimento econômico, se as argumentações teóricas se verificarem no estado.

Para isso, adotando o modelo de Crespo-Cuaresma e Wörz (2003) equação (2.9) -, mensurou-se o efeito das exportações segmentadas tecnologicamente no crescimento do PIB per capita do Paraná, via o modelo VAR.

O procedimento inicial para a estimação de tal modelo refere-se à investigação quanto à estacionariedade das séries, executadas por meio dos testes Dickey-Fuller aumentado e via o teste Phillips-Perron ${ }^{9}$ (Apêndice B). Em ambos, a hipótese nula de existência de raiz unitária foi rejeitada para a maioria das séries, com exceção da produtividade das exportações mais intensivas em tecnologia e para a produtividade das exportações menos intensivas em tecnologia, encontrando uma ordem de integração l (1).

Com efeito, é comum que a análise dos resultados do VAR seja feita via função resposta ao impulso. Nela, mede-se a sensibilidade de determinadas variáveis a certos choques, contribuindo na identificação quanto à direção e o tempo de reação das respostas aos impulsos (choques) de um desvio padrão sobre os valores atuais e futuros das variáveis do sistema.

\footnotetext{
${ }^{9}$ Para essa investigação, o teste Phillips-Perron utiliza erros-padrão para verificar correlação serial, enquanto que o teste Dickey-Fullerimplementa defasagens adicionais de primeira diferença.
} 
Portanto, essas funções foram usadas na avaliação dos efeitos subsequentes de um choque nas exportações sobre o PIB per capita paranaense. Conforme Crespo-Cuaresma eWörz (2003), esses efeitos podem ser divididos em dois: produtividade e externalidades. Além de testar os dois canais de influência, testouos desagregando as exportações em intensidade tecnológica.

Destarte, na Figura 1(c) e 1(d), tem-se o efeito do choque da produtividade das exportações mais intensivas em tecnologia e da produtividade dos outros produtos, respectivamente, sobre o crescimento do PIB per capita. Observa-se que o efeito do choque de ambas é positivo, não sendo, contudo, permanente seus efeitos, dissipando-se rapidamente. Ora, como o Paraná detém vantagem comparativa na produção dos bens primários (especialmente pela alta produtividade), a agregação de valor que é feita especialmente na indústria de baixa tecnologia garante certa vantagem competitiva, conseguindo inserir tais bens internacionalmente, tendo um diferencial de produtividade frente aos produtos domésticos (não exportados). Tais fatos justificam o choque positivo que a produtividade das exportações dos outros bens sobre o crescimento do PIB per capita.

Já no caso da produtividade das exportações mais intensivas em tecnologias, a resposta do PIB per capita é positiva e perdura por um período um pouco maior que a das exportações dos outros produtos. Isso é justificável pelas próprias características de tais bens, os quais, para conseguirem se inserir internacionalmente precisam efetivamente se diferenciar devido a forte concorrência internacional que se tem.

Figura 1. Função resposta ao impulso - Resposta do crescimento do PIB per capita - Paraná

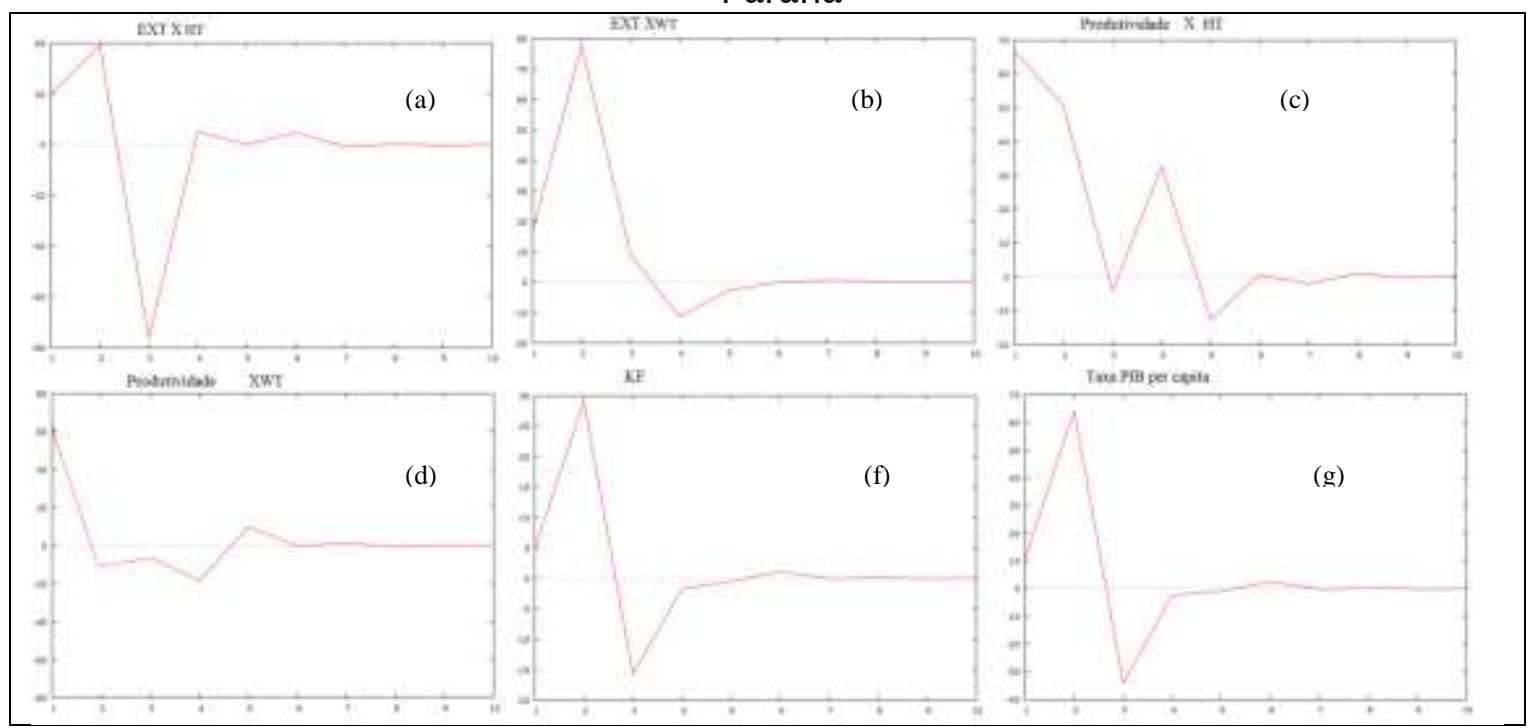

Fonte: Resultado da pesquisa.

Nota: (a) choque nas externalidades das exportações dos bens mais intensivos em tecnologia; (b) choque nas externalidades das exportações dos outros bens; (c) choque na produtividade dos bens mais intensivos em tecnologia; (d) choque na produtividade dos outros produtos; choque no KF; choque no próprio crescimento do PIB per capita.

Na figura 1 (b), tem-se o choque das externalidades das exportações dos outros produtos sobre a taxa de crescimento do PIB per capita, apresentando uma 
resposta inicial positiva. Esse resultado é de suma importância haja vista que a pauta exportadora do Paraná é formada, em sua maioria, por produtos deste segmento. Nesse sentido a sua fomentação tende a gerar não só resultados diretos no PIB, mas também indiretos, que não se anulam imediatamente, prosseguindo com os efeitos multiplicadores no transcorrer do tempo (até o quarto ano).

Ao mesmo tempo, a taxa de crescimento do PIB per capita também responde de forma positiva a um choque nas externalidades dos níveis mais intensos em tecnologia. No entanto, seus efeitos se anulam de forma mais rápida quando comparados aos outros produtos exportados, apresentando, na sequência, um impacto negativo [figura 1(a)]. De acordo com Crespo-Cuaresma e Wörz (2003), os bens mais intensivos em tecnologia tendem a promover maiores externalidades positivas sobre a economia. A própria Teoria da Base Exportadora argumenta que os principais motivos de um setor exportador gerar efeitos positivos são pelo efeito-renda e, principalmente, pelo efeito encadeamento para trás e para frente no processo produtivo. Com efeito, a indústria de média-alta intensidade tecnológica cresceu significativamente nos últimos anos. No entanto, esse mesmo segmento é o que mais importa no Paraná ${ }^{10}$. Por consequência, isso indica que tais unidades produtivas não estão desenvolvendo forte encadeamento, sem a presença das indústrias fornecedoras na região, precisando importar para operar. Tal fato diminui o efeito final na geração de emprego e renda desse segmento industrial, não contribuindo significativamente (em termos, especialmente, de tempo) para o crescimento econômico do estado quando considerados seu efeito via externalidade.

Enfim, as exportações são parte do PIB, influenciando-o diretamente; no entanto, comprova-se a existência de um impacto que vai além dessa participação. No caso do Paraná, esse efeito é intensificado por qualquer tipo de exportação. No entanto, como a grande massa da inserção externa do estado é de bens menos intensivos em tecnologia, detendo certa vantagem comparativa nessa produção, a magnitude desse efeito tende a ser maior. Tal fato encontra embasamento na teoria de Ricardo (1821), o qual defende que as economias tendem a se especializar na produção e exportação de bens ou fatores encontrados em abundância. Conforme essa teoria, uma economia relativamente dotada de madeira, por exemplo, aproveitando-se disso, passaria a se especializar na produção de bens como papel e celulose - uma vez que a madeira é um fator abundante para a economia. De fato, isso se confirma, pois, atualmente, a estrutura produtiva do Paraná é pautada em níveis tecnológicos menos avançados, com a maior parte de sua produção voltada para a indústria de baixa intensidade tecnológica, conforme demonstrado por FILHO e RAIHER, 2012).

Cabe ressaltar, entretanto, que embora o Estado tenha vantagens produtivas nestes outros produtos, menos intensivos em tecnologia, a pequena exportação dos bens mais intensivos em tecnologia gera um impacto no seu dinamismo econômico. Sendo assim, se fomentado tal atividade exportadora, conseguindo intensificar ainda mais os efeitos de externalidades, os resultados finais podem ser ainda mais positivos.

\footnotetext{
${ }^{10}$ No ano de 2010, o nível de média-alta intensidade tecnológica era responsável por cerca de $44 \%$ de toda a importação paranaense.
} 


\section{CONSIDERAÇÕES FINAIS}

O presente trabalho procurou investigar a relação existente entre a estrutura da pauta exportadora paranaense e o seu crescimento econômico.

Primeiramente, pôde-se perceber que as exportações paranaenses cresceram de forma significativa durante o período analisado. Atrelado a isso, apresentou uma elevada diversificação, permitindo minimizar as vulnerabilidades, com menor fragilidade da economia frente às oscilações de demanda externa ou preço, por exemplo.

Quanto a sua vantagem comparativa, está fortemente atrelada à exportação de bens da indústria de baixa tecnologia e de produtos não industriais, no entanto, nos últimos anos, vem apresentando certa relevância da indústria de média alta tecnologia na pauta exportadora do estado.

E ambos apresentam um impacto positivo sobre o crescimento do PIB per capita, choque que se percebe via a produtividade e a externalidade. E é neste sentido que se justifica a demanda por políticas públicas que venham aumentar a produtividade desses produtos, elevando ainda mais a eficiência, impulsionando ainda mais o crescimento paranaense. Dentre essas políticas, reformas estruturais e de infraestrutura deveriam ser priorizadas a fim de reduzir os custos de logística dos produtos paranaenses. Além dessas, uma possível redução nos custos tributários incidentes na produção de bens voltados à exportação aumentaria as vantagens dos produtos paranaenses diante de grandes produtores internacionais.

Não se pode deixar de ressaltar também a importância de avanços tecnológicos naqueles segmentos menos intensivos em tecnologia, nos quais o Paraná detém vantagem comparativa, os quais tem um peso significativo na pauta exportadora. Ou seja, bases estruturais capazes de reunir elementos de desenvolvimento tecnológico, de infraestrutura e de políticas voltadas ao estímulo da exportação desses bens devem ser definidas, pois estes são elementos fundamentais para a superação das dificuldades existentes e, principalmente, para melhorar o desempenho do exportador paranaense.

Uma ressalva deve ser feita quanto à exportação dos bens mais intensivos em tecnologia: embora apresentem um impacto positivo, seu efeito indireto não é tão longo, podendo se torna até negativo no transcorrer do tempo. E o principal responsável por isso é a falta de um encadeamento produtivo completo - com a presença de indústrias fornecedoras de bens intermediários e de capital.

Dessa forma, se investimentos em P\&D, em infraestrutura e incentivos diversos forem dados a esses segmentos, possivelmente as indústrias de média-alta tecnologia apresentarão um papel mais relevante na economia paranaense no decorrer dos anos, dado o peso que estas vêm adquirindo na estrutura produtiva do estado e todo o encadeamento que podem vir a apresentar, podendo-se ter um impacto na economia bem maior do que o observado no transcorrer do período analisado.

\section{REFERÊNCIAS}

AMABLE, B. International Specialisation and Growth. Structural Change and Economic Dynamics, v. 11, n. 4, p. 413-432, 2000. 
ARAÚJO, R. A.; LIMA, G. T.A structural economic dynamics approach to balanceof-paymentsconstrained growth. Cambridge JournalofEconomics, Vol. 31, n. 5, p. 775-774, 2007.

AVERBUG, A. Abertura e integração comercial brasileira na década de 90. In Giambiagi, F. \& Moreira, M. M., editors, A Economia Brasileira nos Anos 90.BNDES, 1999.

BARRO, R. J.; SALA-I-MARTIN, X. Technological Diffusion, Convergence, and Growth.Journal of Economic Growth v.2, p. 1-26. 1997.

CRESPO-CUARESMA, J.; WÖRZ, J. On Export Composition and Growth. University of Vienna, Department of Economics, Vienna, Austria; and Vienna Institute for International Economic Studies (WIIW), Vienna, Austria, 17 p, $2003 .$. Disponível em: <http://www.wiiw.ac.at/pdf/crespo_woerz_etsg_2003.pdf>. Acessoem 28 de março de 2013.

FEDER, G. On exports and economic growth. Journal of Development Economics, Elsevier, v.12, p. 59-73, 1983.

Findlay, R.Growth and development trade models. In: Jones, R.W. e P.B. Kenen, eds. Handbook of international economics. Amsterdam, North-Holland, 1984.

FILHO, M. A. S. A., RAIHER, A. P. Padrão tecnológico da indústria paranaense e o crescimento econômico. Revista Brasileira de Gestão e Desenvolvimento Regional, v. 9, n. 2, p. 96-119, maio/ago 2013.

FURTADO, A. T.; CARVALHO, R. Q. Padrões de intensidade tecnológica da indústria brasileira: um estudo comparativo com os países centrais. Perspec, São Paulo, v.19, n.1, p. 70-84, jan/mar. 2005.

GALIMBERTI, J. K. Composição das Exportações e Crescimento Econômico - O Brasil no período de 1989-2005. In: Instituto de Pesquisa Econômica Aplicada IPEA. (Org.). Prêmio Ipea - CAIXA 2007: monografias premiadas. 1ed. Brasília: Instituto de Pesquisa Econômica Aplicada - IPEA, v.1, p. 497-542, 2007.

GALIMBERTI, J. K.; CALDART, W. L. As exportações e o crescimento econômico: análise dos municípios do Corede Serra - 1997-04. Ensaios FEE, Porto Alegre, v. 31, n. 1, p. 87-112, ago. 2010.

GOMES,E.C.; FATINEL, V.D. O impacto da taxa de câmbio e da renda mundial nas exportações de calçados gaúchos. Disponível em:

$<$ http://cdn.fee.tche.br/eeg/6/mesa14/O_Impacto_da_Taxa_de_Cambio_e_da_R enda_Mundial_nas_Exportacoes_de_Calcados_Gauchos.pdf $>$. Acesso em: dez 2014. 
GROSSMAN, G. M.; HELPMAN, E. Comparative advantage and long-run growth. American Economic Review, v. 80, p. 796-815, 1990.

HATZICHRONOGLOU, T. Revision of the High-Technology Sector and Product Classification. OECD Science, Technology and Industry Working Papers, OECD Publishing.1997.

IPEADATA. Banco de Dados Macroeconômicos e Regionais. Disponível em <http://www.ipeadata.gov.br/>. Acesso em: 2013.

LAMONICA, M. T.; FEIJO, C. A. Crescimento e industrialização no Brasil: uma interpretação "luz" das propostas de Kaldor. Revista de Economia Política, v.31, p. 1-20, 2011.

LAURSEN, K. Trade Specialisation, Technology and Economic Growth: Theory and Evidence from Advanced Countries, Cheltenham, UK and Lyme, US, 2000.

MIGLIORINI, S. M. dos S. Indústria paranaense: formação, transformação econômica a partir da dédaca de 1960 e distribuição espacial da indústria no início do século XXI. Revista Eletrônica Geografar, Curitiba, v. 1, n. 1, p.62-80, jul/dez 2006.

LOURENÇO, G. M. Economia Paranaense: Restrições conjunturais e Avanços estruturais. Curitiba, 1999. Revista FAE, Curitiba, p.1-8, v.2, n.3, set./dez. 1999.

LOURENÇO, G. M. Economia Paranaense: rótulos históricos e encaixe recente na dinâmica brasileira. Revista Análise Conjuntural, Curitiba, v.27, n.11, nov/dez 2005.

MIGLIORINI, S. M. dos S. Indústria paranaense: formação, transformação econômica a partir da dédaca de 1960 e distribuição espacial da indústria no início do século XXI. Revista Eletrônica Geografar, Curitiba, p.62-80, v. 1, n. 1, jul/dez 2006.

NORTH, D. Location Theory an Regional Economic Growth. Journal of Political Economy, v 63, n. 3, p.243-258, 1955.

PENEDER, M. Industrial structure and aggregate growth. StructuralChangeandEconomic Dynamics, vol. 14, p. 427-448, 2003.

PINHEIRO, A. C. O crescimento da produtividade total dos fatores e a estratégia de promoção de exportações: uma revisão da evidência internacional. Pesquisa $e$ Planejamento Econômico - PPE, Rio de Janeiro, n.1, v.22, p.1-34, abr. 1992.

RIBEIRO, N. C. Exportações e crescimento económico: O caso dos países em coesão. Dissertação (Mestrado) - Universidade de Aveiro, Aveiro, 2010. Disponível em: <https://ria.ua.pt/handle/10773/5958>. Acesso em 10 de abril de 2013. 
RICARDO, D. Principles of political economy and taxation.Londres: John Murray, 1821.

Submetido em 07/07/2015

Aprovado em 30/12/2015

\section{Sobre as autoras}

\section{Eduarda Machoski}

Aluna do programa de Mestrado em Economia Regional pela Universidade Estadual de Londrina

Endereço para correspondência: Rua Horácio Antunes Mendes, 621, Condomínio Raul Pinheiro Machado, Bl06 Ap34, Jardim Carvalho. 84015 - Ponta Grossa - PR - Brasil

E-mail: eduarda_machoski@hotmail.com

\section{Augusta Pelinski Raiher}

Docente do curso de Economia e do Programa de Pós-Graduação em Ciências Sociais na Universidade Estadual de Ponta Grossa.

Endereço para correspondência: Rua Cruz Machado, 1848, Vila Rio Branco. 84174420 - Castro Paraná - Brasil.

E-mail: apelinski@gmail.com 


\section{APÊNDICES}

Apêndice A. Critério Akaike (AIC), Bayesiano de Schwarg (BIC) e de HannanQuinn (HQC) na determinação das defasagens

\begin{tabular}{cccc}
\hline Defasagem & AIC & BIC & HQC \\
\hline 1 & $-12,9$ & $-10,9$ & $-12,7$ \\
2 & $-56,9^{*}$ & $-52,7^{*}$ & $-55,9^{*}$ \\
\hline
\end{tabular}

Fonte: Resultado da pesquisa

Apêndice B. Teste Dickey-Fuller (DF) e Phillips-Perron (PP) para raizunitária

\begin{tabular}{lccc}
\multicolumn{1}{c}{ Variável } & \multicolumn{3}{c}{ DF } \\
& & $\begin{array}{c}\text { Com constante } \\
\text { e tendência }\end{array}$ & PP \\
\hline Taxa de crescimento PIB per capita & $-3,34^{*}$ & $3,77^{*}$ & $-4,04^{*}$ \\
Taxa de cresc. capital físico proporção PIB & $-3,37^{*}$ & $3,57^{*}$ & $-4,20^{*}$ \\
Prod. Exportação alta intens. tec. & $-1,83$ & $-1,33$ & $-1,73$ \\
Primeira Diferença Prod. Exportação alta intens. tec. & $-4,61^{*}$ & $-4,27^{*}$ & $-4,41^{*}$ \\
Prod. Exportação baixa int. tec. & 0,82 & $-3,21$ & 0,10 \\
Primeira Diferença Prod. Exportação baixa int. tec. & $-5,07^{*}$ & $-4,91^{*}$ & $-8,68^{*}$ \\
Externalidade Exp. alta intens. tec. & $-3,12^{*}$ & $-3,46$ & $-5,36^{*}$ \\
Extermalidade baixa int. tec. & $-3,07^{*}$ & $-3,36^{*}$ & $-4,09^{*}$ \\
\hline
\end{tabular}

Fonte: Resultado da pesquisa.

Nota: * Indicam significância a 5\%. 